\title{
Use of Ethno Veterinary Medicine (EVM) in India for Livestock Management Practices: A Review
}

\author{
Insha Mir*, Ankita Rautela and Vidya Nimbalkar \\ Department of Veterinary \& Animal Husbandry Extension Education \\ Guru Angad Dev Veterinary \& Animal Sciences University, Ludhiana, India \\ *Corresponding author
}

\section{A B S T R A C T}

Keywords

Ethno veterinary

medicine,

Livestock,

Management and

practices

Article Info

Accepted:

26 May 2020

Available Online:

10 June 2020
Ethno veterinary practices concern to animal healthcare comprised of belief, knowledge, practices and skills pertaining to healthcare and management of livestock acquired through practical experience and has traditionally been passed down orally from generation to generation. The traditional knowledge of animal healthcare practices requires great attention for pharmaceutical analysis to prospect new drugs in the concerned field. Moreover, they are readily available to the ordinary farmer Therefore, there is a need to adopt and also to find out a way to make available cost- effective and reliable remedies for use in livestock and poultry by utilizing the local resources to substitute the expensive medicines by alternate therapy and are increasingly being used as alternatives to chemical products for improvement of animal health.

\section{Introduction}

Livestock economy plays a major role of our agricultural economics. In rural areas, tribals are still depending on plants and household remedies for curing various veterinary ailments. There has been a rich traditional knowledge about animal health care in India and has also been used for ages by farmers to manage ailments in livestock. Medicinal plants have a long history of use in the treatment of both human and animal diseases. The plant based traditional medicine systems continue to play an essential role in health care, with about $80 \%$ of the world's farmers, shepherds and animal growers relying mainly on traditional medicines for treating routine remedies for their livestock (Lulekal et al., 2008 and Devi et al., 2009).

Livestock raisers everywhere have traditional ways of classifying, diagnosing, preventing and treating common animal diseases. There is a rich and efficient ethno veterinary traditions exist in the villages of India. An Ethno veterinary remedy is accessible, easy to 
prepare and administer, at little or no cost at all to the farmer and provides a simple cost effective and efficacious option to the small and marginal dairy farmers who can hardly afford costly conventional treatment options. This will result in significant reduction in long way in stalling the emergence of antimicrobial resistance (AMR) which is major emerging public health concern now a day.

\section{Ethno veterinary practice in India}

In India, veterinary science can be classified into codified traditions and folk medicine. It has a documented history of around 5000 years. The codified knowledge exist in the form of texts manuscripts and the folk health practices largely remain undocumented which are passed on from one generation to the other by word of mouth. There has been a rich traditions and indigenous knowledge about animal healthcare and remedies are based locally on available herbs. Rich and efficient ethno veterinary traditions still exist in the villages of India comprised of belief knowledge, practices and skills pertaining to health care and management of livestock. The people of far flung rural areas still depend to a large extent upon plant and house hold remedies for curing veterinary ailments. In general, EVM is not restricted to treatment of animal diseases alone, but also involves a myriad of disciplines with all aspects of people's knowledge and practices in animal healthcare, productivity and performance that include their diagnostic and ethological understandings; preventive, primitive and therapeutic skills and treatment; and a wide range of health-related management techniques (Lans et al., 2007).

The role of ethno-veterinary medicine in livestock development is presently realized beyond dispute, especially in the developing countries and is also viewed as a potential tool to overcome the side-effects of modern drugs and promote organic farming in both developing and developed nations. Ethno veterinary medicine differs not only from region to region but also among and within communities which are used extensively and quite effectively for primary health care treatment and maintaining animals productive. Ethno veterinary practices are often cheap, safe, time tested and based on local resources and strengths. These can provide useful alternatives to conventional animal health care (Kumar, 2002). Misuses, abuses and side effects of modern drugs, shrinking financial resources, reluctance of private veterinarians to settle in rural areas, and growing consumer interest in healthfulorganic-food products also provided important stimulus for emergence and recognition of EVM as a cost-effective animal healthcare option not only in developing countries, but also in the developed countries. EVM is recognized as a potential resource that can play pivotal role in grassroots development and poverty alleviation, empowering people by enhancing the use of their own knowledge and resources in the developing countries (Iqbal et al., 2005).

Despite all these odds, ignorance and skepticism, almost $80 \%$ of people in developing countries remained dependent on traditional methods of healing and livestock keeping. Besides treatment of sick animals, EVM also includes traditional animal husbandry practices such as housing types, grazing strategies, supplementary feeding, and calf rearing. Many of these practices are still valuable for sustainable livestock development and to improve health and productivity of animals.

Medicinal plants are the most commonly used ingredients in the preparation of ethnovet medicines. All parts of the plants, including leaves, bark, fruits, flowers, seeds are used in 
medicinal preparations. Edible earth, especially from termite and ant hills is commonly used in ethnovet preparations e.g. limestone is a commonly used edible type of earth used in decoctions. Also parts and products of animals, such as skin and hides, bones, milk, butter and even urine and dung are ingredients of ethnovet medicines.

Herbs can be used as a good alternative therapeutic aid to costly allopathic medicines/chemotherapy and boosting immune functions in intoxicated conditions and can also effectively complement allopathic medicines in diseased state.

Ethno veterinary information is in danger of extinction because of current rapid change in communities all over the world. Excessive use of some of the wild plants is leading to the destructive harvesting and as loss of local plant diversity.

Therefore, there is a need to generate awareness among the local population towards the sustainable utilization and conservation of these medicinal herbs.

Herbal medicines for veterinary use can be given or prepared in a number of ways:

Fresh herbs are chopped and mixed with food. It is perhaps the ideal way to give herbs when they are available

Dried herbs can be administered by their addition to food or making them into infusions or decoctions by adding hot water for internal or external use

Alcoholic tinctures are given directly or diluted in water, and given orally carefully using a syringe or dropper

Oil infusions or lotions are given externally, for example, by rubbing on sore joints

Commercially prepared tablets or powders are the most commonly seen form of herbal remedy.
Extensively used traditional treatment methods in dairy cattle (Balakrishnan et al., 2009) studied as:

Mastitis- Applying turmeric on udder

Foot and mouth ulcers- Allowing animals to walk in hot sand and applying sand to wounds externally; applying linseed oil and turmeric externally; applying kerosene if the wounds are infested with maggots.

Tympany- Drenching linseed oil along with a mixture of ginger, turmeric and asafetida; keeping the animal's mouth open by tying a piece of wood into it.

Retention of Placenta- Feeding bamboo leaves or a mixture of oil bran and bajra (finger millet) grain.

Diarrhoea- Drenching about $1 \mathrm{~kg}$ fruit pulp extract of Aeglemarmelos and mango seed kernal for 2-3 days.

\section{Anti bacterial/ antiviral/ antiseptic}

Turmeric - (Curcuma longa) - curcuminoids

Garlic - Anti viral - Allium sativum - sulfurcontaining compounds alliin, ajoene, diallylpolysulfides, vinyldithiins, Sallylcysteine, and enzymes, saponins, flavonoids, and Maillard reaction products

Neem - (Azadirachta indica): Neem is important herbal medicine having different active principle azadrachtin, nimbin, salanin, melicin, etc. Neem oil is selectively activates the cell mediated immune response by activating macrophage and lymphocytes. Apart from this have wide range of pharmacological activities

Traditional veterinary medicine, especially, the use of medicinal plants in the treatment of livestock diseases, needs to be scientifically explored. 
In some remote areas, people have great undocumented traditional knowledge about animal diseases, herbal treatments, formulations, etc., but due to modernization, this traditional veterinary knowledge is on the verge of extinction. The only means of acquisition of this knowledge is from what has been passed down over the generations and the lack of interest for traditional veterinary knowledge in the present generation is leading to its extinction.

Therefore, there is a need to prioritize the veterinary herbal sector and it may provide the base line for phytochemical and pharmacological analysis to find out the medicinal properties of important plants

\section{References}

Balakrishnan, V. et al., 2009. Ethno veterinary Studies among Farmers in Dindigul District Tamil Nadu, India:Global Journal of Pharmacology, 3 (1):15-23.

Devi K, Karthikai GD, Thirumaran G, Arumugam R, Anantharaman P. 2009. Antibacterial activity of selected medicinal plants from Parangipettai coastal regions, Indian Journal of Applied science, 7(9):1212-1215.

Iqbal Z, Jabbar A, Akhtar MS, Muhammad G, and Lateef M. 2005. Possible role of ethnoveterinary medicine in poverty reduction in Pakistan: Use of botanical Anthelmintics as an example. Journal of Agriculture and Social Sciences, 1: 187195

Kumar, D. 2000. Ethno veterinary practices in sheep.Central Sheep and Wool Research Institute. Avikanagar, Rajasthan - 304 501, India.

Lans C, Khan TE, Curran MM and McCorkle M.2007.Ethnoveterinary medicine: Potential solutions for large-scale problems. In: Veterinary Herbal Medicine. SG Wynn and BJ Fougère (eds.). Elsevier Health Sciences, 17-32.

Lulekal E, Kelbessa E, Bekele T, Yineger H. 2008. Anethnobotanical study of medicinal plants in ManaAngetu District, southeastern Ethiopia.Journal of Ethnobiologyand Ethnomedicine, 4: 1-10.

\section{How to cite this article:}

Insha Mir, Ankita Rautela and Vidya Nimbalkar. 2020. Use of Ethno Veterinary Medicine (EVM) in India for Livestock Management Practices: A Review. Int.J.Curr.Microbiol.App.Sci. 9(06): 3458-3461. doi: https://doi.org/10.20546/ijcmas.2020.906.407 